\title{
Metody walki semiotycznej w społeczeństwie informacyjnym
}

\author{
Łukasz Iwasiński \\ Instytut Informacji Naukowej i Studiów Bibliologicznych \\ Uniwersytet Warszawski
}

\begin{abstract}
Abstrakt
Cel/teza: Autor wychodzi od postmarksistowskiej tezy mówiącej, że informacja generowana przez korporacje i sprzężone z nimi media masowe pełni funkcję sterowniczą, kontrolną i opresyjną. Dowodzi jednak, że przynajmniej część jej odbiorców (konsumentów) jest zdolna do samodzielnej, krytycznej, refleksyjnej interpretacji narzuconych komunikatów.

Koncepcja/metody badań: Artykuł odwołuje się do postmarksistowskiej teorii komunikacji masowej i jej krytyki dokonanej przez Szkołę Birmingham oraz nurt poststrukturalistyczny. Autor ilustruje owe koncepcje przykładami zaczerpniętymi ze źródeł zastanych oraz własnych obserwacji.

Wyniki i wnioski: Autor przyjmuje, że wielki biznes, w porównaniu z konsumentami, dysponuje znacznie większymi zasobami informacyjnymi i dostępem do środków ich przekazywania, kolonizując procesy komunikacji masowej. Podważona jednak zostaje teza, jakoby konsumenci byli zmanipulowani i bezbronni, biernie przyswajając komunikaty generowane przez informacyjnych hegemonów wraz z narzuconymi przez nich interpretacjami. Wyrazem aktywnej i krytycznej postawy konsumentów jest podejmowana przez nich walka semiotyczna. W artykule zaprezentowane zostały jej metody. Omówiono pojęcia subwersji i culture jammingu. Przedyskutowano także wpływ rozwoju technologii komunikacyjnych, zwłaszcza Internetu na komunikowanie masowe jako takie i formy semiotycznego oporu.

Oryginalność/wartość poznawcza: $\mathrm{W}$ artykule przedstawiono nowe formy i potencjalne kierunki rozwoju semiotycznej walki w epoce Web 2.0. Wyrażono przekonanie, że działania subwersywne ulegają upowszechnieniu, a zarazem - jak ma to miejsce w przypadku memów - często nabierają bardziej rozrywkowego, niż ideologicznego charakteru.
\end{abstract}

\section{Słowa kluczowe}

Informacja. Komunikacja masowa. Społeczeństwo informacyjne. Subwersja. Walka semiotyczna.

Otrzymany: 6.11.2014. Poprawiony: 17.03.2015. Zaakceptowany: 25.03.2015.

\section{Wprowadzenie}

Mówi się, że we współczesnym społeczeństwie ten, kto ma informacje oraz kontroluje środki ich przekazu, ten ma władzę (Castells, 2000, 20). Postmarksistowscy krytycy kulturowi od zarania namysłu nad komunikowaniem masowym ${ }^{1}$ zwracali uwagą na narastającą dysproporcję w zasobach informacji i dysponowaniu środkami ich przekazu między światem korporacji, wielkim przemysłem a konsumentami. W tym nurcie refleksji podkreśla

${ }^{1}$ Zob. klasyczne prace z kręgu Szkoły Frankfurckiej, zwłaszcza (Horkheimer \& Adorno 1994). 
się związki mediów i wielkiego biznesu; w wielu interpretacjach w generowanej przez czołowe media informacji dostrzega się przekaz służebny wobec interesów korporacji stanowiący wręcz formę zawoalowanej reklamy, albo w sposób pośredni wspierający ich władzę, poprzez propagowanie określonej wizji ładu społecznego, wartości, stylu życia. Teresa Święćkowska zauważa, że korporacje za pośrednictwem przemysłu PR subsydiują w znacznej mierze produkcję medialną, formując w ten sposób wybory konsumentów:

[Przemysł PR] dostarczając informacje i ponosząc koszty jej produkcji, wpływa na wybory klientów i obywateli. Ci, którzy przygotowują materiały dla prasy i innych mediów, preparują je pod kątem określonych ram interpretacji, to oni wybierają i definiują problem, narzucając tym samym możliwy zakres jego rozwiązań (Święćkowska, 2006, 73).

\title{
Z kolei Piotr Żuk stwierdza:
}

\begin{abstract}
Granice między treścią komunikatów reklam a innymi typami informacji są bardzo płynne - sprzedaż i promocja 'właściwego zachowania jednostki i porządku społecznego' odbywa się bowiem non stop w różnych formach przekazu: od telewizyjnych seriali, poprzez tzw. programy gospodarcze, po programy informacyjne - wszędzie reklamuje się pożądane zachowania i sposoby myślenia (Żuk, 2006, 49).
\end{abstract}

A zatem w tej perspektywie przyjmuje się, że rynkowi potentaci, za pomocą bogatego arsenału narzędzi komunikacji marketingowej, korzystając ze swej informacyjnej przewagi (w tym wspomnianego wyżej wpływu na media), dążą do kontroli i manipulacji znacznie gorzej poinformowanych konsumentów. Owa informacyjna asymetria ${ }^{2}$ pozwala im utrzymywać, utrwalać i legitymizować dominację. Według Święćkowskiej, zasięg alternatywnych źródeł informacji i schematów interpretacji, wytwarzanych tradycyjnie przez grupy, czy siły opozycyjne do korporacyjnych, takie jak np. związane z ruchem antyglobalistycznym, jest ograniczony $^{3}$ (Święćkowska, 2006, 73). Konsument postrzegany jest tu jako bierny odbiorca zestandaryzowanej informacji, interpretujący ją zgodnie z intencją nadawców; niemal dowolnie przez nich kształtowany, bezsilny wobec ich informacyjnej hegemonii. Komunikowanie między wielkim przemysłem (czy to bezpośrednie, za pomocą jawnej reklamy, czy zapośredniczone przez podporządkowane mu media) a konsumentami, pojmowane jest nie jako wymiana informacji, lecz jej jednokierunkowa transmisja, a sama informacja pełni w tym modelu funkcję sterowniczą, kontrolną i opresyjną (McQuail, 2007, 72).

Perspektywa ta, jakkolwiek wciąż ma swych rzeczników (Żuk, 2006, 64), podważona została już w połowie lat 60 . XX w., a więc u zarania społeczeństwa informacyjnego ${ }^{4}$. Zauważono, że dysponowanie informacją i środkami jej przekazu niekoniecznie pozwala modelować, urabiać konsumenta, ponieważ jest on zdolny do własnej, autorskiej interpretacji

2 Oczywiście świat korporacji zajmuje nadrzędną pozycję również w aspekcie ekonomicznym, a nie tylko informacyjnym. W niniejszym artykule przedmiotem zainteresowania jest jednak dominacja informacyjna. Oba wymiary dominacji są zresztą ze sobą ściśle powiązane. Naturę owego związku zrozumieć pozwala teoria Pierre’a Bourdieu, analizująca konwersje różnych typów kapitału i przemoc symboliczną (Bourdieu, 2005).

3 Trudno przewidzieć czy przelewająca się przez świat kapitalistyczny w ostatnich latach fala protestu, skupiona m.in. wokół ruchu oburzonych czy Occupy zmieni tę sytuację. Dotychczas niewiele na to wskazuje.

${ }^{4}$ Jeśli przyjąć lata 60. i 70. XX w. za okres krystalizowania się tego typu społeczeństwa i powstania pierwszych jego teoretycznych koncepcji (Goban-Klas \& Sienkiewicz 1999, 42-44; Muraszkiewicz, 2004, 14). 
informacji, dzięki czemu może wyzwolić się od opanowanego przez korporacyjne przekazy symbolicznego porządku. W tej tezie tkwi ważne założenie, że każdą informację da się zinterpretować na różne sposoby, nadawać jej można różny sens, znaczenie.

\section{Poststrukturalistyczny model interpretacji informacji}

Przyjmijmy następujący schemat:

znaki + składnia $=$ dane

dane + kontekst $=$ informacja $($ Roman, 2012, 19).

Komunikat traktuję tu jako synonim informacji, a poprzez komunikację rozumiem przekaz informacji.

A zatem dane to dowolny ciąg znaków niepoddanych procesowi interpretacji. Jeśli umieścimy je w jakimś kontekście i poddamy narzuconemu przez ów kontekst procesowi interpretacji, przypisane zostanie im określone znaczenie. W ten sposób staną się informacją (komunikatem). Rozróżnienie między danymi a informacją nie ma tu charakteru obiektywnego, lecz leży w gestii odbiorcy, który postrzega dane w określonym kontekście i dokonuje ich interpretacji, przypisując określony sens (mówimy tu więc o informacji w sensie infologicznym, w opozycji do jej sensu datalogicznego) (Roman, 2012, 21).

$\mathrm{Na}$ konteksty pośredniczące w procesie interpretacji informacji składają się oddziałujące w nieświadomy sposób na odbiorcę, zakorzenione w kulturze jak i przedzałożenia wypływające z wyznawanych przez niego wartości, a niekiedy równieź świadome decyzje interpretatora - wypływające np. z jego interesów. Ponieważ takich kontekstów jest wiele (potencjalnie nieskończenie wiele), interpretacja wszelkich informacji może być nieustannie rewidowana. Każda interpretacja nadająca sens informacji jest więc jedynie mniej lub bardziej chwieją i doraźną konstrukcją. Owe sensy można zawsze przewartościować odwołując się do innego kontekstu - interpretacja informacji nigdy nie będzie obiektywna i ostateczna. Postulat ten, oparty na poststrukturalistycznym modelu poznania, najbardziej skrajny wyraz znalazł w pismach Jacquesa Derridy. Można by rzec, że radykalny poststrukturalizm ujmuje rzeczywistość społeczną jako zbiór informacji, które mogą być dowolnie rekontekstualizowane i przekształcane w nowe informacje.

Jak pisze David Howarth, Derrida stał na stanowisku, iż powtórzenie danego znaku zawsze prowadzi do przekształcenia jego sensu przez kontekst (Howarth, 2008, 72). Jednocześnie żadna aktualizacja nie zrywa zupełnie z poprzednimi (tzn. wynikającymi z poprzednich kontekstów) znaczeniami - wszak taka sytuacja prowadziłaby do informacyjnego chaosu, niemożności komunikacji. Czytelność komunikatów gwarantuje iterowalność - czyli powtórzenie, ale naznaczone różnicą. Konsekwencją iterowalności jest nierozstrzygalność - niemożność ostatecznego rozstrzygnięcia sensu danego znaku czy informacji. Według Howartha

Derrida nie zakłada ani pełnej reprodukcji znaczeń, czego skutkiem byłaby nasza niewrażliwość na różnice znaków w poszczególnych kontekstach, ani pełnej alteracji, czego rezultatem byłaby niemożność rozpoznania przez nas znaku w różnych kontekstach, w których jest artykułowany (Howarth, 2008, 71). 
Wnioski z poststrukturalistycznego modelu interpretacji informacji do analizy komunikacji społecznej zaczerpnęli w latach 60. i 70. XX w. przedstawiciele studiów kulturowych ze Szkoły Birmingham. Schemat stworzony przez jej czołowego przedstawiciela Stuarta Halla w 1973 r. i w kolejnych latach rozwijany (Hall, 1973; 1980), z łatwością zaadaptować można na potrzeby opisu komunikacji między światem korporacji a konsumentami. Hall przyjął, że znaczenie danej informacji nie jest zdeterminowane przez nadawcę (tu: wielki biznes transmitujący swój przekaz konsumentowi za pośrednictwem reklamy czy szeroko pojętego marketingu i powiązanych z nim mediów); każdy przekaz jest zawsze wieloznaczny, może zostać różnie odczytany przez odbiorcę (konsumenta). Hall wprowadził kategorie kodowania i dekodowania. Nadawca koduje informację w określony sposób (tzn. umieszcza w wybranym kontekście, chcąc narzucić taką a nie inną interpretację). Odbiorca może pozostawać $\mathrm{w}$ ramach kodu dominującego (inaczej: preferowanego), a więc przyjąć zaproponowany kontekst, zdekodować informację wedle woli nadawcy. Z drugiej strony ma zdolność odczytania komunikatu wbrew zamierzeniom nadawcy - co Hall określił jako dekodowanie opozycyjne. Wymaga ono od odbiorcy zrozumienia swej pozycji, wyjścia poza narzucany kontekst, zdystansowania się od niego i świadomego przeciwstawienia. Istnieje też możliwość dekodowania wynegocjowanego. Zachodzi ono wtedy, gdy odbiorca pozostaje w ramach hegemonicznej zależności, akceptuje nadrzędną znaczeniową ramę, ale porusza się w jej obrębie bardziej spontanicznie i samodzielnie, do pewnego stopnia przekształca, indywidualizuje sensy:

Dekodowanie w ramach wersji wynegocjowanej mieści w sobie zarówno elementy akceptacji, jak i sprzeciwu (...). Przyznaje ono uprzywilejowaną pozycję dominującym definicjom (...), rezerwując dla siebie prawo tworzenia zastosowań bardziej adekwatnych do lokalnych warunków (Hall, 1980, za: Storey, 2003, 20).

A więc korporacje nadają określone informacje (czy to bezpośrednio za pomocą reklamy i innych narzędzi marketingowych czy pośrednio, posługując się mediami) i przedstawiają je w określonym kontekście, chcąc kontrolować ich interpretację wśród odbiorców. Z oczywistych względów życzą sobie by „dekodowanie było zgodne z kodowaniem”, jednak nie mogą tego „nakazać ani zagwarantować” (Storey, 2003, 19). Konsument może dowolnie zdekodować znaczenie wszelkich informacji, odwołując się do innych kontekstów. Taka optyka kwestionuje, a w każdym razie problematyzuje model warunkowania zachowań odbiorców oparty na paradygmacie komunikacji masowej, widzianej jako jednokierunkowa transmisja informacji sterowana przez posiadające informacyjną przewagę korporacje.

We współczesnym świecie niewątpliwie mamy do czynienia z informacyjną asymetrią między korporacjami a konsumentami. Jednak, jak twierdzi wyrastająca z dorobku Halla szkoła studiów kulturowych, nie musi oznaczać to zniewolenia tych ostatnich. Konsumenci są zdolni do samodzielnej interpretacji wszelkiego typu docierających do nich komunikatów. Co więcej - potrafią podjąć walkę semiotyczną, a więc zawłaszczają nadawane przez korporacje i media informacje (a niekiedy wykorzystują inne elementy ich informacyjnej infrastruktury) do wyrażenia znaczeń opozycyjnych. W ten sposób poniekąd neutralizują informacyjną asymetrię. 


\section{Subwersja i culture jamming}

Formę walki semiotycznej stanowi subwersja oraz culture jamming. Subwersję rozumieć można jako nienormatywne użycie generowanych przez informacyjnych hegemonów komunikatów, a więc wykorzystanie ich dla własnych celów wbrew intencjom nadawcy, a często wbrew ogólnie przyjętym normom. Z kategorią subwersji związane jest zjawisko culture jamming (w polskich przekładach funkcjonuje jako zagłuszanie bądź klinowanie kultury, zakłócanie fal kultury czy też prowokacja kulturowa). Stanowi ono, najogólniej rzecz ujmując, grę (często ironiczną) z komunikatami generowanymi przez - by użyć określenia Jurgena Habermasa - kolonizujące przestrzeń publiczną korporacje i podporządkowane ich interesom media. W najszerszym znaczeniu termin ten odnosi się do wszelkich aktów dywersji skierowanych przeciw wszechobecnej, produkowanej przez korporacje i media informacji (Dery, 2010).

Konsumenci są skazani na funkcjonowanie w realiach informacyjnej asymetrii, nie są w stanie stworzyć realnej konkurencji dla informacyjnych hegemonów. Mogą jednak, by tak rzec, pasożytować na nich, na różne sposoby utrudniać ich funkcjonowanie, a także obnażać ich manipulatorskie treści - inspirując odbiorców do krytycznej interpretacji (czyli, mówiąc językiem Stuarta Halla, wynegocjowanego bądź opozycyjnego zdekodowania). A zatem działania z zakresu culture jamming polegają na walce o zdemaskowanie i skompromitowanie opanowującej przestrzeń publiczną, osaczającej konsumentów informacji i próbie wyrwania ich spod jej władania (Krzysztofek, 2011; Krajewski, 2006, 60; Carducci, 2006, 116-138). Koncentrują się na rekontekstualizacji komunikatów, deformowaniu ich pierwotnego, zamierzonego przez nadawcę sensu, zdyskredytowaniu zwłaszcza konsumpcjonistycznej propagandy i wszelkich umacniających pozycję korporacji ideologii. Stanowią - jak pisze Neomi Klein - „otwartą niezgodę na to, by marketing, wykupując naszą przestrzeń publiczną, odebrał nam prawo głosu i stał się informacyjnym monopolistą" (Klein, 2004, 298).

Pojęcie culture jamming ukute zostało w połowie lat 80 . XX w. przez członków grupy Negativland, tworzącej dźwiękowe kolaże, bazujące m.in. na produkcjach komercyjnego popu, jakkolwiek sama idea jest starsza - stanowi wszak bezpośrednie nawiązanie do realizowanej przez sytuacjonistów idei detournment (Debord, 2006). A sięgając głębiej, można przywołać wydawane na przełomie lat 20. i 30. XX w. nowojorskie, satyryczne pismo Ballyhoo ironicznie komentujące prostackie i natarczywe reklamy, publikujące ich parodie (Klein, 2004, 322). Często o culture jammingu mówi się w kontekście dekonstruowania, przeinaczania reklam w celu ich skompromitowania. Ściślej działania te należałoby określić mianem tzw. subvertisingu (kombinacja słów subversion - subwersja i advertising - reklama) albo adbustingu ${ }^{5}$. Typowym celem adbusterów stają się reklamowe billboardy ${ }^{6}$, zwłaszcza te eksponujące najsilniejsze marki. Jak pisze Jakub Wandachowicz:

${ }^{5}$ Typowe przykłady, to zamiana nazw marek i haseł reklamowych - np. "McDonald's" na "WC Donald's", “Nokia. Connecting People” na "Nokia. Cancering People” [„Nokia. Łączenie ludzi” na „Nokia. Powodowanie u ludzi raka”, "Nike. Just do it” na "Nike. Do it just” [„Nike. Po prostu to zrób” na „Nike. Zrób to uczciwie"] itp.

${ }^{6}$ Od końca lat 70. działa szereg organizacji zorientowanych na tego typu działalność - do najbardziej znanych należą amerykańska Billboard Liberation Front - http://www.billboardliberation.com/ oraz australijska Billboard Utilising Graffitists Against Unhealthy Promotions - http://www.bugaup.org. Zob. też (Pluciński, 2003, 111-117). 


\begin{abstract}
Chyba nie ma już sensu pisać o reklamie; o jej hipnotycznym wpływie na tzw. masowego odbiorcę; o trywializacji idei, jakiej dokonuje; o merkantylnej, rynkowej wizji świata, którą kreuje nowoczesny marketing; o wywoływaniu sztucznych potrzeb i pragnień, masowej produkcji marzeń; o stereotypach, które są w reklamie wzmacniane i powielane... Wszystko to brzmi jak banał, choroba została zdiagnozowana dawno temu i takie tezy nikogo już dziś nie dziwią. Jednocześnie świadomość manipulacji, jakiej dokonuje reklama, splata się w nas z silnym przeświadczeniem, że od tej nowej wizji świata uciec się nie da. Reklama wciska się wszędzie, wypełnia każdą najmniejszą lukę w krajobrazie (zarówno tym rzeczywistym, jak i wirtualnym, który stanowi najlepsze środowisko dla propagowania nowych trendów) (...) Obowiązkowym elementem kampanii reklamowych są billboardy. Do nich należy sfera tzw. przestrzeni publicznej. Wirtualne potrzeby, kreowane głównie przez media (telewizję, radio, Internet), muszą zostać odpowiednio zwielokrotnione, wzmocnione, odbite - w związku z tym język rynkowych kodów towarzyszy nam na każdym kroku, stając się niejako naszym naturalnym środowiskiem. To dlatego ulice, domy, miasta zamieniają się powoli w gigantyczne słupy ogłoszeniowe ${ }^{7}(. .$. Jedynym wyjściem jest swoiście pojęta semantyczna partyzantka, dekonstrukcja, sabotaż, dywersja, techniki subwersywne, prowokacja, gra, śmiech, ironia (Wandachowicz, 2005).
\end{abstract}

Subwersja to nie tylko zawłaszczanie konkretnych komunikatów, celem wprowadzenia zakłócenia w komunikacji. Obejmuje ona również zakrojone na szerszą skalę przedsięwzięcia. Niekiedy dąży się do wprowadzenia do infosfery własnych treści, kontestujących porządek wspierany przez informacyjnych hegemonów. I tak, np. aktywistka Carly Stasko dostrzegłszy, iż obrazy kobiet prezentowane w komunikatach reklamowych, narzucane przez nie kanony piękna, wpędzają dziewczyny w kompleksy, już w wieku zaledwie 16 lat stworzyła amatorski magazyn, pt. „Uncool”. Bazując m.in. na opatrzonych sarkastycznymi komentarzami przeróbkach czy wycinankach z podporządkowanej marketingowi przemysłu urody kobiecych pism, podjęła walkę z owymi wizerunkami. Odwołując się do słów Rafała Drozdowskiego, można stwierdzić, że mamy tu do czynienia nie tylko z przekształcaniem wyizolowanego komunikatu

w wyniku którego zaczyna on oznaczać coś zupełnie innego niż w swojej pierwotnej postaci (Drozdowski, 2006, 134).

To przykład

wytwarzania i upowszechniania alternatywnych kampanii, swego rodzaju kontrkampanii, które stylistycznie nawiązują do swoich pierwowzorów, jednakże odwracają ich wymowę (Drozdowski, 2006, 134).

W subwersywnych działaniach studia kulturowe widzą przejaw siły, aktywnej i krytycznej postawy konsumentów. Subwersja jest nieodzownym elementem społeczeństw, których aktorzy świadomi są, że dla informacyjnej dominacji korporacji nie ma alternatywy, ale dzięki krytycznej interpretacji narzuconych komunikatów oraz manipulowaniu dostępnymi informacyjnymi zasobami hegemonów, potrafią przeciwstawiać się ich presji.

\footnotetext{
7 Rafał Drozdowski stwierdza, że billboardy traktują tkankę urbanistyczną miasta jak jedną wielką konstrukcję nośną (Drozdowski, 2006, 135). Ciekawym przyczynkiem do tych rozważań jest casus dużej łódzkiej kamienicy, usytuowanej w samym centrum miasta, w reprezentacyjnym i atrakcyjnym punkcie na rogu ulic Mickiewicza i Kościuszki, która od lat jest opuszczona i stanowi wyłącznie „wieszak” na wielkoformatowe reklamy.
} 


\section{Nowe formy subwersji w epoce Web 2.0}

Jak już powiedziałem, na gruncie postmarksitowskiej teorii komunikacji masowej, to informacje zakodowane przez korporacje i podporządkowane im media stanowiły źródło znaczeń dla konsumentów. Rozwijane przez Szkołę Birmingham studia kulturowe zgadzały się z tą teorią co do dominacji korporacyjno-medialnego konglomeratu, ale przyjmowały, że konsumenci niekoniecznie owe znaczenia akceptują, często odrzucają. Dziś, w czasach postępującego rozwoju społeczeństwa informacyjnego, schemat komunikacji masowej dezaktualizuje się, zastępowany przez komunikację sieciową. W idealnym modelu komunikacji sieciowej znaczenia mogłyby być negocjowane w toku debaty między równorzędnymi odbiorcami-nadawcami. Taka sytuacja praktycznie nie ma miejsca - komunikacja społeczna w aktualnych realiach łączy elementy (wciąż odgrywającej bardzo istotną rolę) komunikacji masowej z elementami komunikacji sieciowej, a nawet tam, gdzie mamy do czynienia z tą ostatnią, poszczególne węzły mają mniejsze lub większe znaczenie, te silniejsze dążą do kontroli przepływów, stąd w ramach sieci zawsze tworzy się hierarchia. Niemniej jednak zorganizowana na zasadzie sieciowego modelu wymiana informacji stwarza pole dla pluralizacji i demokratyzacji komunikacji społecznej - z punktu widzenia problematyki niniejszego artykułu istotne jest dopuszczenie do głosu szerokich rzesz konsumentów. Proces ten zaobserwować można w obszarze Internetu drugiej generacji, zwanego Web 2.0 - a więc opartego na treściach dostarczanych przez samych użytkowników (Krzysztofek, 2008).

Schemat pierwszej generacji sieci - bazującej na treściach dostarczonych przez wąską grupę specjalistów, przeznaczonych tylko do odczytu - nie różnił się aż tak bardzo od schematu komunikacji masowej. Stwarzał szansę bardziej zindywidualizowanej komunikacji, ale nie kreował otwartego forum dyskusji, wciąż opierał się na władzy powiązanych z korporacjami gatekeeperów (osób bądź instytucji kontrolujących transfer informacji w mediach) i odgórnym indeksowaniu zasobów. Konsument w takim systemie nadal zdany był na komunikaty generowane przez informacyjnych hegemonów, zorientowanych przede wszystkim na wypracowanie ekonomicznego zysku. Z kolei w ramach Web 2.0 do obiegu medialnego nowe treści może wprowadzić każdy użytkownik. Co więcej, na gruncie tego modelu zasoby Internetu hierarchizowane są w oparciu o tagowanie, a więc definicje nadawane przez samych konsumentów. Stąd taksonomia - narzucanie definicji przez wąską grupę, zastąpiona zostaje folksonomią - definiowaniem przez użytkowników. Sytuacja ta umacnia pozycję konsumenta w semiotycznej walce. Jak pisze Kazimierz Krzysztofek, wraz $\mathrm{z}$ rozwojem komunikacji sieciowej narasta wiara $\mathrm{w}$

możliwość odzyskania władzy nad własnymi symbolami, samodefiniowania się i samopotretowania przez upublicznianie dyskursów mniejszościowych; słowem - wiara w demokrację semiotyczną $\left(\right.$ Krzysztofek, 2008) ${ }^{8}$.

Rosnąca rola komunikacji sieciowej - przynajmniej potencjalnie - umożliwia łatwiejszą cyrkulację informacji między konsumentami; mają oni szansę dzielić się wiedzą na temat

8 Wzrost interaktywności Internetu to proces, a cezura oddzielająca Web 1.0 od Web 2.0 jest umowna. Takie zestawienie służy lepszemu wyeksponowaniu konsekwencji ewolucji sieci. Można przyjąć, że przedstawiona charakterystyka obu rodzajów sieci stanowi ich typy idealne (Weber, 1985, 81-90). 
towarów, recenzować je, wymieniać doświadczeniami, upubliczniać zastrzeżenia i skargi. Konsumenci mogą włączyć się w liczne internetowe społeczności zainteresowane określonymi dziedzinami konsumpcji albo blogosferę, współtworząc wolny dyskurs na temat produktów czy też problemów na jakie, jako konsumenci napotykają. Mają dostęp do stron, jak i aplikacji, które wyszukują pożądane towary i porównują wedle wybranych kryteriów. Tym samym dostają narzędzia umożliwiające im kontrolowanie korporacji, weryfikowanie medialnych treści, pilnowanie jakości produktów i innych szeroko pojętych konsumenckich interesów ${ }^{9}$. W końcu Internet staje się efektywnym kanałem szerzenia komunikatów kontestujących korporacyjno-medialną hegemonię.

Niebagatelne znaczenie dla powstania nowych form subwersji ma rozwój technologii cyfrowej, która dała niemal każdemu możliwość dokonywania przeróbek najróżniejszych upowszechnianych przez media treści (informacji, jak i utworów muzycznych, seriali, filmów, gier komputerowych, oprogramowania), a pojawienie się Web 2.0 stworzyło forum ich prezentacji. Ten pęd do manipulowania oferowanymi przez media dobrami znajduje wyraz w jednej z metafor współczesnej kultury - kulturze remiksu (Lessig, 2008; Gulik et al., 2011). Remiks stał się ważnym, być może podstawowym narzędziem subwersji. Jakkolwiek wykorzystywanie go do celów kulturowego oporu ma znacznie dłuższą tradycję, dziś taktyka remiksu stała się dostępna dla każdego posiadacza komputera. Jej amatorzy dewastują dystrybuowane przez media treści niczym aktywiści culture jammingu billboardy, ale na nieporównywalnie większą skalę. Co jednak charakterystyczne, w praktykach tych dochodzi do zacierania granicy między krytyką a zabawą - ta druga staje się nawet istotniejsza. Koncentrują się one w dużej mierze na produkcji z obszaru kultury i rozrywki, jednak tu chciałbym wskazać na ich inną, szczególną formę, mianowicie internetowy mem, który stanowi w istocie remiks informacji. Pojęcie memu wywodzi się z biologii ewolucyjnej i pierwotnie oznaczało podstawową, samoreplikującą się jednostkę informacji przekazywanej w danej kulturze (Dawkins, 2007, 244-252). Tu jednak interesuje nas inny jego sens. Ponieważ nie funkcjonuje ono w tym znaczeniu w oficjalnych słownikach, warto przywołać kilka definicji obecnych w Internecie. Zatem mem to:

śmieszna idea, obrazek, powielany w internecie (Mem, 2014);

dowolna, chwytliwa porcja informacji, która może przybrać wiele form. Stąd też memy występują pod postacią obrazków, filmików, zdań, a nawet słów. Niezależnie od kształtu i wzoru, wszystkie spełniają jeden warunek - popularności w sieci (Woś, 2013).

Jest to więc zwykle przetworzenie jakiejś bieżącej medialnej informacji, mające w założeniu komentować zwięźle i żartobliwie rzeczywistość oraz posiadające zdolność do szybkiego (wirusowego) rozprzestrzeniania się w Internecie. Dziś niemal każdy nośny komunikat pojawiający się mediach, zwłaszcza niosący jakiś potencjał ironiczny, zostaje w ten sposób zremiksowany. Rola memów wzrosła wraz z dostępnością i łatwością technologii do ich produkcji i upowszechniania. Istnieją całe serwisy internetowe poświęcone memom (np. mem.pl), memami każdego dnia zalewane są serwisy społecznościowe, funkcjonuje mnóstwo poświęconych im facebookowych profili (np. hipsterski maoizm), regularnie donoszą

\footnotetext{
9 Z drugiej strony sieciowa komunikacja wykorzystywana bywa przez korporacje do manipulowania konsumentem. Wydaje się jednak, że jej emancypacyjny potencjał przeważa nad potencjałem zniewalającym.
} 
o nich nawet niektóre serwisy informacyjne (jak gazeta.pl ${ }^{10}$ ). Memy stanowią niekoniecznie narzędzie walki z korporacyjno-medialnym ładem, często są dla konsumenta współczesnej infosfery po prostu sposobem na odreagowanie jej absurdów, swoistym wentylem bezpieczeństwa czy po prostu niezobowiązującą rozrywką (Rid, 2013, 129), stąd być może trafniej byłoby nazwać je grą, a nie walką semiotyczną. Zapewne bywają one jednak też gestem sprzeciwu wobec zamazującego faktyczny obraz rzeczywistości zalewu informacji - data glut, zdiagnozowanego już lata temu przez Theodore'a Roszaka (Roszak, 1994). Zarazem niektórzy dostrzegają w nich narzędzie oporu wobec dominujących komunikatów (Huntington, 2013). Wraz z rozwojem i wzrostem dostępności technologii komunikacyjnych można spodziewać się coraz większej obecności memów w przestrzeni społecznej. Będą one pełnić różne funkcje - od pozbawionej jakiegokolwiek ideologicznego zabarwienia zabawy, po krytyczny komentarz społeczny.

Zdecydowanie zaangażowani ideologicznie aktywiści culture jammingu również na inne sposoby z powodzeniem wykorzystują dobrodziejstwa technologii cyfrowej i Web 2.0. Nie tylko chodzi o zamianę pędzla czy markera na wielofunkcyjne programy do cyfrowej obróbki materiałów graficznych, ale przede wszystkim o łatwiejszą ingerencję w informacyjną infrastrukturę ${ }^{11}$, a dzięki temu szansę głębszej ingerencji w korporacyjno-medialny porządek. Wymowny jest przykład duetu Yes Menów ${ }^{12}$, którzy zasłynęli m.in. jako autorzy fikcyjnych stron internetowych, udających witryny najróżniejszych korporacji, dzięki czemu zyskali dostęp do mediów jako ich rzekomi przedstawiciele, ujawniając ich nieetyczne, działające na szkodę konsumentów praktyki i kompromitując je, przy okazji nie zostawiając suchej nitki na legitymizującej korporacyjno-medialną hegemonię neoliberalnej ideologii jako takiej.

Dodajmy, że rozwój technologii cyfrowej i komunikacji sieciowej wywarł wpływ także na nowe teoretyczne koncepcje jednostki w społeczeństwie. Warto tu wspomnieć ideę indywidualizmu sieciowego Barry'ego Wellmana, którego istotą jest wyzwolenie się z dawnych, sztywnych i zamkniętych grup, na rzecz samodzielnego budowania otwartych relacji (Wellman, 2001). Z kolei wizja jednostki superwzmocnionej (Stalder, 2010) wskazuje na rosnące znaczenie autonomicznych, charyzmatycznych aktorów społecznych zmian, zdolnych do wywoływania działań o istotnym politycznym, gospodarczym czy kulturowym wydźwięku, potrafiących niejednokrotnie zaszkodzić wielkim mediom i korporacjom, czego przykładem może być Julian Assange (2013).

${ }^{10}$ Serwis ten dn. 16.10.2014 r. na głównej stronie, w samej czołówce podawanych informacji zamieścił wiadomość z serwisu deser.pl, pt. „Nowe sprężynowe logo dla Polski niezbyt spodobało się internautom... Ich propozycje są lepsze” (http://deser.pl/deser/51,111858,16812947.html), zawierającą zbiór memów odnoszących się do prezentowanych w mediach propozycji nowego logo Polski. Stworzenie logotypu, który oficjalnie ma stać się wizytówką Polski na świecie, związane jest z trzema rocznicami ważnych wydarzeń historycznych przypadających w 2014 r.: 25-lecia odzyskania niepodległości, 15-lecia wstąpienia do NATO i 10-lecie akcesji do Unii Europejskiej, zob. http://logodlapolski.pl/

${ }^{11}$ Mamy wtedy do czynienia z tzw. mediami taktycznymi (Nayar, 2010, 100-102; Nacher, 2012, 186-210).

12 http://theyesmen.org/, zob. film “The Yes Men Fix The World”: https://www.youtube.com/watch?v=OazUh0Ym8rc 


\section{Wnioski}

Postmarksistowska krytyka komunikacji społecznej spod znaku Szkoły Frankfurckiej osunęła się w absurd, uznając, że opanowana przez korporacyjno-medialny przekaz infosfera jako całość ma charakter opresyjny. Studia kulturowe dostrzegły fakt, iż funkcjonujący w realiach informacyjnej asymetrii konsumenci są zdolni do tworzenia własnych, uzależnionych od osobistych kontekstów interpretacji korporacyjno-medialnych komunikatów. Oponenci tego stanowiska zarzucali mu co prawda nadmierny optymizm, zwracając uwagę, że prowadzić ono może do przeceniania niezależnych interpretacji odbiorców informacji, marginalizowania asymetrycznego charakteru komunikacji, a w konsekwencji zanegowania jakiejkolwiek opresji i manipulacji ze strony informacyjnych hegemonów (Strinati, 1998, 202-203). Warto także zauważyć, że owi hegemoni niejednokrotnie dążą do zawłaszczenia, a mówiąc językiem studiów kulturowych - inkorporacji - opozycyjnych wobec nich komunikatów generowanych przez konsumentów, zamieniając ich postulaty w kolejny produkt, a ich samych - w nową rynkową niszę. Tworzy się więc sytuacja specyficznego napięcia między korporacjami, które przechwytują, asymilują i pacyfikują wymierzone w nich przekazy, a odbiorcami, którzy wynajdują coraz to nowe sposoby wyrażenie swego oporu.

Podejmowane przez konsumentów formy walki (czy też gry) semiotycznej są jednak mocnym argumentem na rzecz tezy o ich potencjale do refleksyjnego, krytycznego odczytywania dominujących komunikatów i możliwości wyrwania się spod symbolicznej przemocy korporacji i mediów.

\section{Bibliografia}

Assange, J. (2013). Cypherpunks. Wolność i przyszłość Internetu. Gliwice: Helion.

Bourdieu, P. (2005). Dystynkcja. Społeczna krytyka władzy sadzenia. Warszawa: Wydaw. Nauk. Scholar.

Carducci, V. (2006). Culture Jamming: A Sociological Perspective. Journal of Consumer Culture 6(1), 116-138.

Castells, M. (2000). The Rise of the Network Society. The Information Age: Economy, Society and Culture. Oxford: Malden-Blackwell.

Dawkins, R. (2007). Samolubny gen. Warszawa: Prószyński i S-ka.

Debord, G. (2006). Społeczeństwo spektaklu oraz rozważania o społeczeństwie spektaklu. Warszawa: PIW.

Dery, M. (2010). Culture Jamming: Hacking, Slashing, and Sniping in the Empire of Signs [online]. Mark Dery [14.10.2014], http://markdery.com/?page_id=154

Drozdowski, R. (2006). Obraza na obrazy. Strategie społecznego oporu wobec obrazów dominujacych. Poznań: Wydaw. UAM.

Goban-Klas, T.; Sienkiewicz, P. (1999). Społeczeństwo informacyjne. Szanse, zagrożenia, wyzwania. Kraków: Wydaw. Fundacji Postępu Telekomunikacji.

Gulik, M.; Kaucz, P.; Onak, L., red. (2011). Remiks. Teorie i praktyki. Kraków: Rozdzielczość Chleba.

Hall, S. (1973). Encoding and Decoding in The Television Discourse. Birmingham: University of Birmingham.

Hall, S. (1980). Encoding/decoding. In: S. Hall, D. Hobson, A. Lowe, P. Willis (eds.) Culture, Media, Language. London: Hutchinson, 128-138

Horkheimer, M.; Adorno, T. (1994). Dialektyka oświecenia. Warszawa: IFiS PAN.

Howarth, D. (2008). Dyskurs. Warszawa: Oficyna Naukowa.

Huntington, H. (2013). Subversive Memes: Internet Memes as a Form of Visual Rhetoric. [online] Selected Papers of Internet Research 3, [14.10.2014], http://spir.aoir.org/index.php/spir/article/view/785 
Klein, N. (2004). No Logo. Izabelin: Świat Literacki.

Krajewski, M. (2006). POPamiętanie. Gdańsk: Słowo/obraz terytoria.

Krzysztofek, K. (2011). Zagłuszanie kultury masowej [online]. Kultura i Historia, 20 [14.10.2014], http://www.kulturaihistoria.umcs.lublin.pl/archives/3001

Krzysztofek, K. (2008). Web 2.0 jako dobrodziejstwo [online]. Computerworld, 27 maja (14.10.2014), http://www.computerworld.pl/artykuly/324065/Web.20.jako.dobrodziejstwo.html

Lessig, L. (2008). Remix: Making Art and Commerce Thrive in the Hybrid Economy. London: Penguin Press.

McQuail, D. (2007). Teoria komunikowania masowego. Warszawa: PWN

Mem (2014). Wikisłownik, Wolny stownik [online], [14.10.2014], http://pl.wiktionary.org/w/index. php?title $=$ mem\&oldid $=4488793$

Muraszkiewicz, M. (2004). Społeczeństwo informacyjne i praca. W: B. Sosińska-Kalata, K. Materska i W. Gliński (red.) Społeczeństwo informacyjne i jego technologie. Warszawa: Wydaw. SBP, 13-28. Nacher, A. (2012). Rubieże kultury popularnej. Kraków: Galeria Miejska Arsenał.

Nayar, P. K. (2010). An Introduction to New Media and Cybercultures. Oxford: John Wiley \& Sons.

Pluciński, P. (2003). Uwolnić billboardy, czyli rzecz o subvertisingu. Kultura Popularna, 3, 111-117.

Rid, T. (2013). Cyber War Will Not Take Place. New York: Oxford University Press.

Roman, K. (2012). Podstawy zarzadzania informacją. Toruń: Wydaw. Naukowe UMK.

Roszak, T. (1994). The Cult of Information: A Neo-Luddite Treatise on High Tech, Artificial Intelligence, and the True Art of Thinking. Berkeley: University of California Press.

Stalder F., (2010). Leaks, Whistle-Blowers and the Networked News Ecology [online]. n.n. -- notes \& nodes on society, technology and the space of the possible [15.03.2015], http://felix.openflows. com/node/149\#fn1

Storey, J. (2003). Studia kulturowe i badania kultury popularnej. Kraków: Wydaw. UJ.

Strinati, D. (1998). Wprowadzenie do kultury popularnej. Poznań: Zysk.

Święćkowska, T. (2006). Rynkowe środki przekazu - ekonomia polityczna, ideologia, dominacja. Subsydiowanie informacji jako forma jej kontroli na przykładzie praktyk public relations. W: P. Żuk (red), Media i wtadza. Warszawa: Wydaw. Nauk. Scholar, 65-78.

Wandachowicz, J. (2005). Przestrzeń publiczna [online]. Purpose, 11, sierpień [14.10.2014], http:// www.purpose.com.pl/archiwum/mag-nr_11/felieton/mag-przestrzen_publiczna.html

Weber, M. (1985). Obiektywność poznania w naukach społecznych. W: A. Chmielecki,

S. Czerniak, J. Niżnik, S. Rainko (red.) Problemy socjologii wiedzy. Warszawa: PWN, 45-100.

Wellman, B., (2001). Physical Place and Cyberplace: The Rise of Personalized Networking. International Journal of Urban and Regional Research 25(2), 227-252.

Woś, A. (2013). Co to jest mem internetowy? [online]. Cafesenior.po [14.10.2014], http://cafesenior. $\mathrm{pl} /$ co-to-jest-mem-internetowy/

Żuk, P. (2006). Media a kontrola społeczna w czasach „wolności rynkowej”. W: P. Żuk (red.), Media i wtadza. Warszawa: Wydaw. Nauk. Scholar, 39-64.

\title{
Methods of Semiotic Struggle in the Information Society
}

\begin{abstract}
Purpose/thesis: The author begins with a post-Marxist thesis which assumes that the mass information generated by corporations and media is an instrument of control and oppression. He argues,
\end{abstract}


however, that at least some of its recipients (consumers) are capable of autonomous, critical, reflective interpretation of imposed messages.

Approach/methods: The paper refers to the post-Marxist theory of mass communication and its critique by the Birmingham School and poststructuralist thinkers. The author illustrates these concepts with observed examples or cases obtained from desk research.

Results and conclusions: The author assumes that big business, compared to consumers, manages much greater resources of information and access to the media, colonizing thus processes of mass communication. However, the thesis that consumers are manipulated, passively absorbing messages generated by information hegemons along with imposed interpretations, is questioned. Consumers' active and critical attitude manifests itself in a semiotic fight. The paper presents the methods of this fight, examines the notions of subversion and culture jamming and discusses the impact of the development of communication technologies, in particular the Internet, on mass communication and forms of semiotic resistance.

Originality/value: The paper presents new forms and trends in the development of semiotic struggle in the Web 2.0 era. The author expresses the belief that subversive activities are becoming more common, and at the same time - as is the case with Internet memes - often are of more entertaining than ideological nature.

\title{
Keywords
}

Information. Mass communication. Information society. Subversion. Semiotic struggle.

Dr ŁUKASZ IWASIŃSKI jest absolwentem Wydziału Organizacji i Zarzadzania Politechniki Łódzkiej (2006) oraz socjologii na Uniwersytecie Łódzkim (2007), gdzie w 2013 r. uzyskat także stopień doktora nauk spotecznych w zakresie socjologii. Obecnie jest adiunktem w Instytucie Informacji Naukowej i Studiów Bibliologicznych Uniwersytetu Warszawskiego. Wazniejsze publikacje: Technologia - wszechrynek - konsumpcja. W: Kultura Wspótczesna 2007, 4, 166-188; Cywilizacyjne warunkowania wspótczesnego konsumpcjonizmu. W: D. Walczak-Duraj(red.), Folia Sociologica 33. Dyskursywne i niedyskursywne obrazy rzeczywistości, Łódź, Wydaw. UŁ 2008, 317-336; Czy prosumpcja sprzyja emancypacji? Dylematy zarzadzania konsumentami. W: Ł. Sutkowski, M. Zawadzki (red.), Nurt krytyczny w naukach o zarzadzaniu, Warszawa, Difin, 2014, 163-177

\author{
Kontakt $z$ autorem: \\ lukiwas@gmail.com \\ Instytut Informacji Naukowej i Studiów Bibliologicznych \\ Uniwersytet Warszawski \\ ul. Nowy Świat 69 \\ 00-927 Warszawa
}

